\title{
A TUTELA JURISDICIONAL COLETIVA E O SISTEMA DE PRECEDENTES NO DIREITO BRASILEIRO
}

\author{
Gabriel Aparecido Bastos Almeida \\ Universidade do Oeste Paulista - UNOESTE, Presidente Prudente, SP. E-mail: gabriel pac96@hotmail.com
}

\section{RESUMO}

O advento do Estado social ocasionou o surgimento de direitos de natureza coletiva e conflitos de massa que tornaram necessária a criação de mecanismos de tutela coletiva, ante a incapacidade do processo clássico em promover a adequada tutela desses litígios. Buscando resolver essa situação, foi criado um microssistema de tutela coletiva com o objetivo de proteger direitos difusos, coletivos e individuais homogêneos. Todavia, esse sistema revelou-se incapaz de resolver o excessivo número de demandas que abarrotam o Judiciário, tornando necessária a constituição de um sistema de precedentes vinculantes, que conferisse maior coerência e estabilidade jurisprudencial. Diante desse contexto, o presente estudo teve por objetivo analisar o sistema brasileiro de tutela coletiva, através do exame das ações coletivas e dos incidentes processuais de resolução de lides repetitivas que integram o sistema de precedentes brasileiro. A metodologia seguiu o método dedutivo, com emprego de pesquisa doutrinária e legal acerca do tema pesquisado.

Palavras chave: tutela; ação; coletiva; precedentes; obrigatórios.

\section{COLLECTIVE JUDICIAL PROTECTION AND THE SYSTEM OF PRECEDENTS IN BRAZILIAN LAW}

\begin{abstract}
The advent of the social state caused the emergence of rights of a collective nature and mass conflicts, making it necessary to create mechanisms for collective tutelage, given the incapacity of the classical process to promote the adequate protection of these new litigation. Aiming to solve this situation, a system of collective tutelage has been created, whose objective is the protection of diffuse, collective and individual homogeneous rights. However, this system proved incapable of solving the excessive number of demands that overwhelm the Judiciary, which has made it necessary to establish a system of binding precedents in order to achieve greater consistency and stability in the jurisprudence. In view of this context, the present study aimed to analyze the Brazilian system of collective tutelage, through the examination of collective actions and procedural incidents of resolution of repetitive cases that are part of the Brazilian precedent system. The methodology followed the deductive method, using doctrinal and legal research on the researched topic.
\end{abstract}

Keywords: protection; action; class; precedents; binding. 


\section{INTRODUÇÃO}

Com o advento do Estado liberal na passagem do século XVIII para o XIX, em decorrência das revoluções burguesas ocorridas no período, o Estado sofreu uma considerável redução de seu poder, passando a ser o responsável, tão somente, por proporcionar que a autonomia da vontade fosse adequadamente exercida nas relações entre os particulares. Nesse período, o Poder Legislativo se sobrepôs aos demais e o Judiciário perdeu sua autonomia, tornando-se um Poder nulo, responsável apenas por declarar o texto da lei.

Sob a égide do Estado liberal, o direito processual se desenvolveu a partir de um viés individualista, preocupado apenas com a resolução dos litígios entre indivíduos e deixando de lado a regulamentação dos conflitos coletivos. Essa foi, inclusive, a ideologia que orientou a processualística civil no século passado, época em que o Direito Processual Civil possuía forte influência liberalista, advinda dos diplomas processuais europeus construídos a partir da política liberal do século XIX.

A partir do início do século XX, com a elaboração da Constituição Mexicana de 1917 e a Constituição de Weimer de 1919, surgiu um novo tipo de Estado, de feitio intervencionista e ocupado em assegurar os chamados direitos de segunda dimensão, para cuja realização não basta a abstenção do Estado, sendo necessária a implementação de "[...] programas governamentais de desenvolvimento e efetivação de direitos prestacionais, com o propósito de viabilizar a igualdade efetiva perante os bens da vida" (MORAES, 2016, p. 342).

Todavia, em virtude da incapacidade financeira de atender adequadamente aos encargos assumidos perante a sociedade, que crescia demograficamente e se tornava cada vez mais complexa, o Estado social entrou em crise na década de 70 , momento em que a procura pelo Poder Judiciário aumentou consideravelmente diante dos novos direitos criados e muitas vezes não devidamente assegurados pelo Estado.

Além disso, os novos direitos deram origem a litígios desconhecidos do Poder Judiciário, como, por exemplo, os relacionados ao trabalho, à saúde e à educação, dentre outros. Com a Declaração Universal dos Direitos Humanos de 1948, surgiram os direitos de terceira dimensão, que são aqueles "[...] interesses transindividuais ou metaindividuais, também conhecidos como direitos coletivos em sentido amplo" (DANTAS, 2016, p. 278). Tais direitos são indivisíveis e têm em comum o fato de que seus titulares são indeterminados, estando unidos apenas por uma situação de fato ou por uma relação jurídica base.

O surgimento de direitos de natureza coletiva e a multiplicação do número de processos tornou necessária a mudança do modo como a tutela jurisdicional era prestada, pois o modelo clássico de processo, de perfil individualista, mostrava-se incapaz de promover a adequada prestação jurisdicional. Buscando criar mecanismos processuais adequados para a tutela coletiva, foram editadas as leis 7.347 (BRASIL, 1985) e 8.078 (BRASIL, 1990) (Código de Defesa do Consumidor), que criaram um microssistema processual coletivo, aplicável a todas as ações coletivas existentes no País, prevendo, inclusive, a tutela coletiva de direitos individuais homogêneos.

A ampliação da tutela coletiva, contudo, não foi capaz de solucionar a crise do número de processos individuais, por diversos motivos de ordem processual e, também, extraprocessual. Diante dessa realidade, foram realizadas diversas reformas legislativas que promoveram, além da ampliação da tutela jurisdicional coletiva, o fortalecimento da força vinculante dos precedentes judiciais e a criação de técnicas processuais de resolução de demandas repetitivas, tudo com o propósito de reduzir o número de demandas judiciais e, consequentemente, tornar a prestação jurisdicional mais célere.

Diante do contexto apresentado, o presente trabalho teve por objetivo analisar o sistema brasileiro de tutela jurisdicional coletiva, através de um breve exame de nosso sistema de precedentes à luz de seus fundamentos pragmáticos e relacionando-o com as ações coletivas, que 
foram observadas sob o enfoque da tutela dos direitos individuais homogêneos. Para cumprir com seu objetivo, o presente trabalho seguiu o método dedutivo, com emprego de pesquisa doutrinária e legal acerca do objeto do estudo. Primeiramente, através de investigação doutrinária, foi traçado um panorama histórico e social acerca da tutela jurisdicional coletiva, e, em seguida, procedeu-se a uma análise das ações coletivas e do sistema precedentes a partir de um exame da legislação.

\section{A TUTELA DOS DIREITOS COLETIVOS}

Como já dito, a sociedade contemporânea se caracteriza pela existência de relações jurídicas massificadas, que têm por objeto direitos de natureza coletiva. A partir dessa realidade social "as crises de direito deixaram de se instalar apenas sobre as relações entre um e outro indivíduo e se expandiram para compreender outras numerosas relações plurilaterais" (THEODORO JR., 2016, p. 912), o que resultou no surgimento de conflitos que envolvem não apenas indivíduos, mas toda a coletividade ou os membros de um grupo social.

A expressão "direitos coletivos" representa o gênero do qual são espécies os direitos difusos, os coletivos (stricto sensu) e os individuais homogêneos. Os dois primeiros são chamados de naturalmente coletivos, pois se caracterizam pela indivisibilidade de seu objeto, que é de titularidade de um grupo, ou mesmo, de uma coletividade de pessoas indetermináveis. Já os direitos individuais homogêneos são chamados de acidentalmente coletivos, pois têm por objeto bens divisíveis, que podem ser fracionados entre os seus titulares (GAJARDONI, 2012, p. 57-58).

O processo clássico, de natureza individual, revela-se incapaz de promover a adequada tutela aos direitos difusos e coletivos, pois tais direitos se caracterizam pela indivisibilidade de seu objeto, o que impede que sejam fracionados entre seus titulares. No que tange aos direitos individuais homogêneos, contudo, a possibilidade de adoção da tutela jurisdicional coletiva não decorre da natureza de tais direitos, mas sim, de uma opção de política legislativa, pois, embora esses interesses possam ser adequadamente tutelados através de processos individuais, a necessidade de reduzir o número de demandas e de tornar mais célere o trâmite processual, fez com que o Legislador permitisse, excepcionalmente, o ajuizamento de ações coletivas para defende-los. Ademais, a tutela de interesses homogêneos por meio de processos individuais, gera o risco de decisões distintas a casos substancialmente idênticos, o que coloca em risco o princípio da igualdade, que representa um dos pilares do Estado Democrático de Direito.

A tutela coletiva de direitos individuais homogêneos, ora é realizada através de ações coletivas, ora através de um "[...] incidente aglutinador de ações originariamente singulares" (THEODORO JR., 2016, p. 912). No primeiro caso, um legitimado coletivo se apresenta em juízo representando os interesses de um determinado grupo de pessoas que sejam titulares de direitos individuais originados de uma mesma situação de fato ou de direito, com o propósito de solucionar a situação de cada uma delas através de um único processo. Já na segunda situação, há uma única decisão acerca de determinada questão de direito, a qual será utilizada para o julgamento das diversas ações individuais em que esteja sendo discutida a mesma questão jurídica.

\section{A TUTELA DE DIREITOS INDIVIDUAIS HOMOGÊNIOS ATRAVÉS DE AÇÕES COLETIVAS}

Nos países de tradição romano-germânica, a origem da tutela coletiva remonta à ação popular (actio popularis) do direito romano, através da qual os cidadãos podiam buscar a defesa de direitos pertencentes à toda a coletividade. Já nos países integrantes do common law, costuma-se afirmar que a origem da tutela jurisdicional coletiva ocorreu no século XII, quando surgiram na Inglaterra alguns litígios envolvendo grupos sociais representados por seus líderes (NEVES, 2016). 
O sistema brasileiro de tutela coletiva foi fortemente influenciado pelas class actions do direito norte-americano. A princípio, contudo, o estudo dessas ações pela doutrina brasileira ocorreu de forma indireta, através de trabalhos de juristas italianos, como Mauro Cappelletti, Michele Taruffo, Vittorio Denti, dentre outros, que, na década de 70, realizaram diversos estudos, com o propósito de criar um sistema de tutela coletiva no ordenamento italiano (CAVALCANTI, 2015). Desse modo, embora a doutrina reconheça a existência da ação popular no direito pátrio desde a era colonial, a tutela coletiva apenas passou a ser desenvolvida cientificamente em nosso país na década de 80 , quando começaram a surgir os primeiros estudos sobre o tema, a partir da doutrina italiana.

O sistema norte-americano é apontado como um dos mais avançados em termos de tutela jurisdicional coletiva, constituindo um verdadeiro marco na história do processo coletivo. Naquele sistema, a disciplina das chamadas class actions está prevista na Federal Rule of Civil Procedure 23, norma federal editada em 1938 (e revisada em 1966), que confere amplo tratamento ao tema, estabelecendo pré-requisitos, hipóteses de cabimento, procedimento, recursos, dentre outros aspectos (CAVALCANTI, 2015).

No direito brasileiro, a evolução das ações coletivas no âmbito legislativo se deu a partir de quatro marcos históricos, quais sejam, a lei 4.717(BRASIL, 1965), a lei 7.347 (BRASIL, 1985), a Constituição Federal (BRASIL, 1988) e a Lei 8.078 (BRASIL, 1990). Todas essas leis compõem um verdadeiro microssistema de tutela coletiva, cujo núcleo é formado pela Lei da Ação Civil Pública (BRASIL, 1985) e pelo Código de Defesa do Consumidor (BRASIL, 1990), que orientam todas as demais normas integrantes desse microssistema.

Necessário salientar, contudo, que os direitos individuais homogêneos apenas passaram a ser abrangidos pelo sistema de tutela coletiva com a edição do Código de Defesa do Consumidor (BRASIL, 1990), que promoveu a ampliação do objeto da Ação Civil Pública, que, sob a égide da lei 7.347 (BRASIL, 1985), tinha cabimento apenas para a tutela de direitos difusos e coletivos (stricto sensu). Somente após a edição do referido diploma, é que foram criadas outras ações coletivas para a defesa dos direitos individuais homogêneos, como, por exemplo, o mandado de segurança coletivo, o habeas data coletivo e o mandado de injunção coletivo.

Cumpre ressaltar que, apesar do direito brasileiro possuir um microssistema coletivo relativamente desenvolvido, as ações coletivas não têm sido capazes de resolver o grande volume de processos individuais que abarrotam o Poder Judiciário. A doutrina tem atribuído essa ineficiência à "[...] inadequação da técnica processual coletiva para a satisfatória resolução dos conflitos de massa" (CAVALCANTI, 2015, p. 386), em decorrência de deficiências técnicas da legislação brasileira, bem como de outras causas de natureza extraprocessual, como, por exemplo, o aumento da consciência jurídica dos cidadãos, a ampliação dos meios de comunicação em massa, o desenvolvimento de novas tecnologias e da oferta de novos produtos, o surgimento de novos direitos, etc.

\section{O SISTEMA DE PRECEDENTES BRASILEIRO SOB A PERSPECTIVA DA LITIGIOSIDADE COLETIVA}

Diferentemente do common law, a criação do sistema de precedentes vinculantes no direito brasileiro teve por objetivo reduzir o número de ações judiciais, através do desestímulo à litigância e da criação de mecanismos de resolução de demandas repetitivas. Em outros termos, Cramer (2016) afirma que a valorização dos precedentes no direito pátrio é motivada não apenas por fundamentos deontológicos, como a segurança jurídica e a isonomia, mas também por fundamentos pragmáticos, que visam tornar mais célere o trâmite processual.

Para alcançar tais objetivos, o novo Código de Processo Civil (BRASIL, 2015) instituiu um sistema de precedentes verticalizado, além de ter reforçado o regime de julgamento dos recursos repetitivos e criado, com inspiração no procedimento-modelo alemão, o incidente de resolução de 
demandas repetitivas (arts. 976 a 987), com o propósito de evitar a dispersão excessiva da jurisprudência (BRASIL, 2010).

$O$ incidente de resolução de demandas repetitivas (IRDR) consiste em um incidente processual que tem por objetivo resolver uma questão de direito que se repete em diversas ações, através de uma decisão aplicável não apenas à causa em que foi instaurado, mas à todas as ações em que a mesma tese esteja sendo discutida. Segundo Marcelo Abelha, "[...] a finalidade precípua do instituto é a proteção do direito objetivo, na medida em que pretende evitar injusta desigualdade de tratamento judicial de casos análogos" (ABELHA, 2016, p. 1377).

Outro mecanismo processual, ampliado pelo novo código (art. 947) (BRASIL, 2015), e que tem o objetivo de pacificar os entendimentos acerca de questões jurídicas de grande repercussão social, contribuindo para a resolução de múltiplas ações judiciais contemporâneas e posteriores a ele, é o incidente de assunção de competência. Trata-se de instituto semelhante ao incidente de resolução de demandas repetitivas, dele se diferenciando, basicamente, por seu caráter preventivo, ou seja, pelo fato de que a sua instauração ocorre antes do surgimento da pluralidade de entendimentos em processos distintos, justamente com o propósito de evitar o surgimento de divergência jurisprudencial.

Além de criar os mencionados incidentes processuais com o propósito de solucionar os litígios de massa, o legislador atribuiu eficácia normativa vinculante aos acórdãos neles proferidos (art. 927, III, CPC) (BRASIL, 2015), visando assegurar, desse modo, a coerência e a estabilidade da jurisprudência. Ademais, o novo código ainda previu que, no caso de desrespeito aos entendimentos firmados em tais incidentes, será cabível o remédio da reclamação para o fim de garantir a sua observância (arts. 985, § 10 e 988, IV, ambos do CPC) (BRASIL, 2015).

Por fim, cumpre ressaltar que o novo código, inspirando-se no sistema common law, inseriu no ordenamento brasileiro os institutos da distinção (distinguishing) e da superação (overruling), que se prestam a possibilitar a operacionalização dos precedentes (CRAMER, 2016). Pelo primeiro, é possível afastar a incidência do precedente a um caso concreto, através da demonstração de que as circunstâncias fáticas do caso em julgamento são diversas daquelas existentes no caso paradigma. A superação, por sua vez, prevista no artigo $927, \S \S 20$ a 4 으, do mencionado diploma (BRASIL, 2015), busca impedir o "engessamento do direito", permitindo que haja a alteração de entendimentos que se mostrarem ultrapassados.

A existência de mecanismos de distinção e superação é de suma importância para a correta aplicação dos precedentes, bem como para o adequado funcionamento da tutela coletiva através dos mencionados incidentes processuais. A possibilidade de distinção decorre da natureza casuística do precedente, que nasce a partir de um caso concreto (salvo exceções, como as decisões em controle concentrado de constitucionalidade) e não de forma abstrata como ocorre com a lei. A superação, por sua vez, é possível em razão da necessidade de atualização do direito, que é uma ciência social e, como tal, está sujeito a mudanças.

\section{CONCLUSÃO}

O sistema brasileiro de tutela coletiva foi concebido com a finalidade de promover maior celeridade e economia processual, através da redução do número de demandas em trâmite no Poder Judiciário. A insuficiência do processo individual clássico para a tutela dos novos direitos, de natureza coletiva, tornou necessária a sistematização de mecanismos adequados para a defesa de tais direitos, seja através de ações coletivas, seja mediante incidentes em ações individuais.

Embora tenham contribuído para a resolução mais célere dos conflitos de massa, as ações coletivas têm se mostrado incapazes de solucionar a crise numérica de processos, que abarrotam o Poder Judiciário e tornam lenta a prestação jurisdicional. Diante desse contexto, o sistema de precedentes vinculantes, instituído pelo Código de Processo Civil (BRASIL, 2015) passa a ser de grande importância para, ao lado das ações coletivas, promover a adequada resolução dos 
conflitos de massa, reduzindo assim, o grande número de ações judiciais em trâmite, sem, contudo, desrespeitar o direito de acesso à justiça (CF, art. 5으, XXXV).

\section{BIBLIOGRAFIA}

ABELHA, Marcelo. Manual de direito processual civil, 6 ed. Rio de Janeiro: Forense, 2016.

BRASIL, Conselho Nacional de Justiça. Justiça em números, Brasília, 2016. Disponível em:<http://www.cnj.jus.br/files/conteudo/arquivo/2016/10/b8f46be3dbbff344931a93357991548 8.pdf>. Acesso em 06 julh. 2017.

BRASIL. Constituição (1988). Constituição da República Federativa do Brasil. Brasília: Senado Federal, 1988.

BRASIL, Senado Federal. Anteprojeto do novo código de processo civil, Brasília, 2010. Disponível em: <https://www.senado.gov.br/senado/novocpc/pdf/Anteprojeto.pdf>. Acesso em 04/07/2017.

BRASIL. Lei no 4.717, de 19 de junho de 1965. Regula a ação popular. Diário Oficial da União, Brasília, 29 jun. 1965. Disponível em: <http://www.planalto.gov.br/ccivil_03/Leis/L4717.htm>. Acesso em: 18 set. 2018.

BRASIL. Lei no 7.347, de 24 de julho de 1985. Disciplina a ação civil pública de responsabilidade por danos causados ao meio-ambiente, ao consumidor, a bens e direitos de valor artístico, estético, histórico, turístico e paisagístico e dá outras providências. Diário Oficial da União, Brasília, 24 jul. 1985. Disponível em: < http://www.planalto.gov.br/ccivil_03/leis/L7347orig.htm>. Acesso em: 18 set. 2018.

BRASIL. Lei no 8.078, de 11 de setembro de 1990. Dispõe sobre a proteção do consumidor e dá outras providências. Diário Oficial da União, Brasília, 11 set. 1990. Disponível em: <http://www.planalto.gov.br/ccivil_03/Leis/L8078compilado.htm>. Acesso em: 18 set. 2018. BRASIL. Lei no 13.105, de 16 de março de 2015. Institui o Novo Código de Processo Civil. Diário Oficial da União, Brasília, 16 mar. 2015. Disponível em: http://www.planalto.gov.br/ccivil_03/_Ato2015-2018/2015/Lei/L13105.htm. Acesso em: 18 set. 2018.

CAVALCANTI, Marcos. Incidente de resolução de demandas repetitivas e ações coletivas, 1 ed. Salvador: Juspodivm, 2015.

CRAMER, Ronaldo. Precedentes judiciais - teoria e dinâmica, 1 ed. Rio de Janeiro: Forense, 2016.

DANTAS, Paulo Roberto de Figueiredo. Curso de Direito Constitucional, 4 ed. São Paulo: Atlas, 2016.

GAJARDONI, Fernando da Fonseca. Direitos difusos e coletivos I - teoria geral do processo coletivo (Coleção saberes do direito - vol. 34), 1 ed. São Paulo: Saraiva, 2012.

MORAES, Guilherme Peña de. Curso de Direito Constitucional, 8 ed. São Paulo: Atlas, 2016.

NEVES, Daniel Amorim Assumpção. Manual de processo coletivo, 3 ed. Salvador: Juspodivm, 2016. 
THEODORO JR., Humberto. Curso de Direito Processual Civil, Vol. III, 49 ed. Rio de Janeiro: Forense, 2016. 